\title{
Struktur Komunitas Makrobentos Pada Kawasan Budidaya dan Non Budidaya Di Pulau Tembelas, Kabupaten Karimun Kepuluan Riau
}

\author{
Raden Faradhiva Prahmawaty, Sapto P Putro dan Riche Hariyati \\ Departemen Biologi, Fakultas Sains dan Matematika, Universitas Diponegoro \\ Jl. Prof Soedharto, SH, Tembalang, Semarang 50275 \\ faradhiva13@gmail.com.
}

\begin{abstract}
The macrobenthos community structure of living organisms in aquatic base, can function as a bioindicator of changes in aquatic environments, are sensitive to any disturbance of environmental changes within a waters. This research aims to determine the effect of different structures of macrobenthos communities in the cultivation environment and noncultivation environment. The research was conducted for 4 months on Tembelas island in 2 areas that were monoculture cultivation and reference area. Abiotic data obtained were substrate grain analysis and total organic analysis of carbon and nitrogen, as well as abiotic environmental parameters such as temperature, $\mathrm{pH}$, salinity and dissolved oxygen. The biotic data obtained in the form of macrobenthos species that were found and the amount in the area was then calculated using non parametric index that were the level of diversity, eveness and abundance, and $\mathrm{T}$ test. The identification result showed the number of species found as many as 24 species in the monoculture location and 42 species at the reference location. Dominant species found in monoculture locations were Costoanachis sp and Anodontia sp. dominant species found in the reference sites were Nuculana sp and Ellobium sp. ShannonWiener $\left(\mathrm{H}^{\prime}\right)$ diversity index value at monoculture location was 2,43, while reference index value index had bigger index value 2,83 . The abiotic quality of monoculture and reference aquatic environments was categorized as good. Based on the result of the research, it can be concluded that reference environment had better macrobenthos diversity value than monoculture environment.
\end{abstract}

Keywords: Makrobenthos, Monoculture, Reference Environment

\begin{abstract}
Abstrak
Struktur komunitas makrobenthos organisme yang hidup di dasar perairan, dapat berfungsi sebagai yaitu sebagai bioindikator perubahan lingkungan perairan, bersifat sensitif terhadap adanya gangguan perubahan lingkungan di dalam suatu perairan. Penelitian ini bertujuan untuk mengetahui pengaruh perbedaan struktur komunitas makrobenthos pada lingkungan budidaya dan lingkungan nonbudidaya. Penelitian dilaksanakan selama 4 bulan di pulau Tembelas pada 2 area yaitu budidaya monokultur dan area referensi. Data abiotik berupa analisis butiran substrat serta analisis total organik karbon dan nitrogen serta parameter lingkungan abiotik seperti suhu, $\mathrm{pH}$, salinitas dan oksigen terlarut. Data biotik yang didapat berupa jenis-jenis makrobenthos yang ditemukan serta jumlahnya di daerah tersebut kemudian dihitung dengan menggunkan indeks non parametric yaitu tingkat keanekaragaman, kemerataan dan kelimpahannya serta uji T. Hasil identifikasi menunjukkan jumlah spesies yang ditemukan sebanyak 24 spesies pada lokasi monokultur dan 42 spesies pada lokasi referensi. Spesies dominan yang ditemukan pada lokasi monokultur yaitu Costoanachis $s p$ dan Anodontia $s p$. spesies dominan yang ditemukan pada lokasi referensi yaitu Nuculana $s p$ dan Ellobium sp. Nilai indeks keanekaragaman Shannon-Wiener (H') pada lokasi monokultur sebesar 2,43, sedangkan nilai indeks lokasi referensi memiliki nilai indeks lebih besar yaitu 2,83. Kualitas abiotik lingkungan perairan monokultur dan referensi tergolong baik. Berdasarkan hasil penelitian dapat disimpulkan bahwa lingkungan referensi memiliki nilai keanegakagaman makrobenthos yang lebih baik dibandingkan lingkungan monokultur
\end{abstract}

Kata Kunci: Makrobenthos, Monokultur, Lingkungan Referensi.

\section{PENDAHULUAN}

Makrobenthos merupakan organisme yang hidup di dasar perairan atau di bagian sedimen dasar perairan, berukuran lebih dari $1 \mathrm{~mm}$ (dapat terlihat jelas atau visible). Makrobenthos meliputi organisme yang hidup pada lumpur, pasir, batu 
kerikil, maupun sampah organik di dasar perairan, hidup menempel, menetap, atau meliang di dasar perairan. Secara umum, makrobenthos (kelompok makrozoobenthos) merupakan detritivor atau scavenger.

Sifat hidup makrozoobentos memberikan keuntungan untuk digunakan sebagai indikator biologi diantaranya memiliki habitat hidup yang menetap. Dengan demikian, perubahan-perubahan kualitas air tempat hidupnya akan berpengaruh terhadap komposisi dan kelimpahannya. Makrozoobentos merupakan komponen biologi untuk pemantauan kualitas perairan terkena dampak dari perubahan kondisi ekologi perairan tersebut (Asra,2009).

Pulau Tembelas merupakan salah satu pulau yang terdapat di Kabupaten Karimun, Kepulauan Riau. Pulau ini digunakan sebagai tambak budidaya Keramba Jaring Apung (KJA) sistem IMTA.

Budidaya merupakan suatu kegiatan pemeliharaan sumber daya hayati yang dilakukan secara terkontrol untuk diambil manfaat/hasil panennya. Salah satu hal penting dalam budidaya ikan adalah pakan alami yang merupakan faktor pembatas bagi keberhasilan budidaya.Kebutuhan pakan alami masih dipasok dari hasil tangkapan di alam yang ketersediaannya sangat fluktuatif. Oleh karena itu, untuk mengantisipasi hal tersebut diperlukan suatu usaha budidaya (Khairuman, 2008).

Aplikasi keramba jaring apung (KJA) menjadi salah satu cara untuk meningkatkan produktif dan berkelanjutan untuk budidaya ikan, didalam beberapa tahun terakhir. Sistem budidaya keramba jaring apung (KJA) berkembang pesat, budidaya sisitem KJA tersebut menjadi salah satu solusi terhadap permasalahan yang sering muncul pada budidaya sistem tambak, yaitu adanya banjir karena tingginya intensitas hujan pada musim tertentu sehingga dapat meninggalkan atau menyapu biota dudidaya (Putro dan Suhartana, 2008; Wijayanti et al., 2009)..

\section{BAHAN DAN METODE}

Tempat dan Waktu: Penelitian dilaksanakan di Laboratorium Ekologi dan Biosistematik Departemen Biologi Undip, dan laboratorium Ce- mebsa, Laboratorium Terpadu Undip. pada bulan juni 2016- Oktober 2017

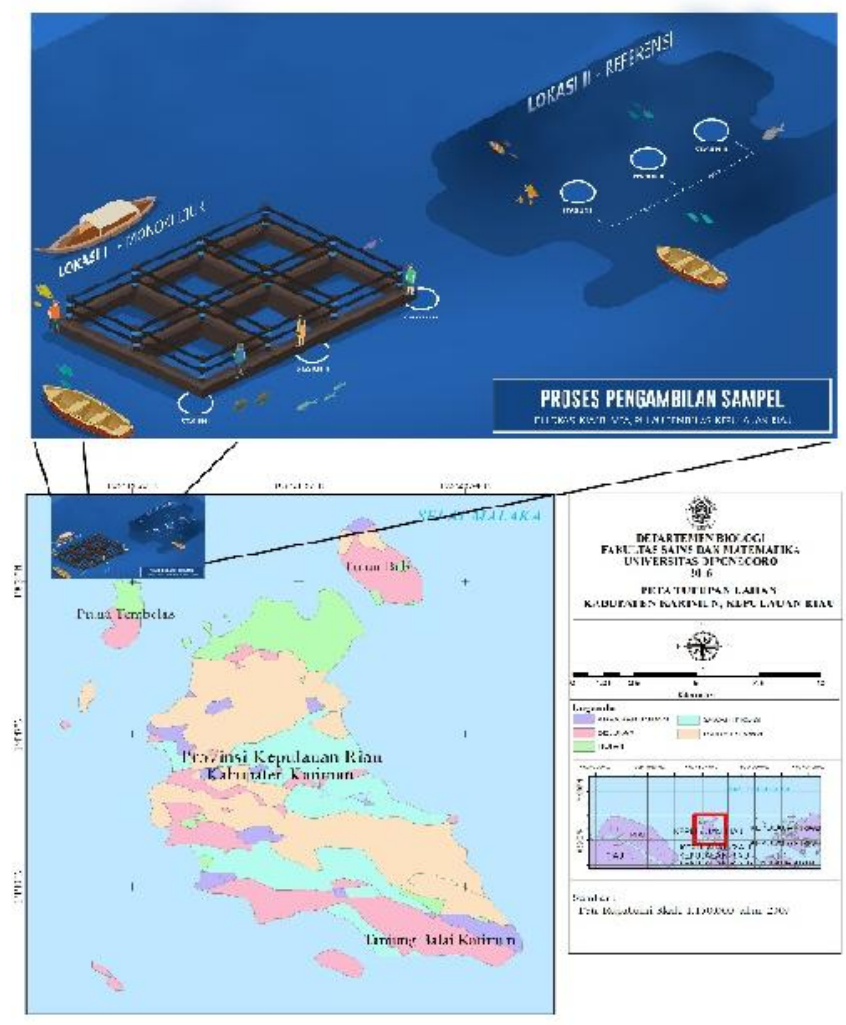

Gambar 1 Peta lokasi penelitian

Alat dan Bahan: adalah ekman grab, water checker, saringan bentos $1 \mathrm{~mm}$, botol sampel, pinset, sarung tangan, cawan petri, kantung plastik, masker, label, kamera, buku identifikasi, alat tulis. Sampel hewan makrobentos, sampel air, sempel sedimen, larutan formalin 4\%, larutan ethanol $70 \%$. Prosedur Penelitian: Pengambilan Sampel, pengukuran faktor fisika-kimia perairan dan pengambilan sampel air, pengambilan dan pengukuran sampel fisika-kimia sedimen, pengambilan sampel makrobentos.

Analisis sampel: Substrat diambil untuk menganalisis kandungan karbon dan nitrogen serta mengetahui komposisi butiran substrat sedimen. Makrobentos diidentifikasi oleh buku identifikasi.

Analisi data: Data yang diperoleh dari hasil penelitian kemudian dicatat dan dianalisi lebih lanjut yaitu struktur komunitas makrobentos: Indeks dominansi (C) dihitung dengan rumus Simpson dalam Odum (1993): 


$$
C=\sum_{i=1}^{n} p_{i}^{2}=\sum_{i=1}^{n}\left[\frac{n_{i}}{N}\right)^{2}
$$

Keterangan :

$\mathrm{C}=$ Indeks Dominansi

$\mathrm{ni}=$ Jumlah individu ke-i

$\mathrm{N}=$ Jumlah total individu

Dengan kisaran menurut Odum (1993) sebagai berikut :

$0<\mathrm{C}<0,5=$ Tidak ada jenis yang mendominasi

$0,5<\mathrm{C}<1=$ Terdapat jenis yang mendominasi

Indeks keanekaragaman $\left(\mathrm{H}^{\prime}\right)$ digunakan

Menurut Indeks Diversitas Shannon-Wienner (krebs, 1985).

$$
H^{\prime}=\sum_{n=i}^{S} \sum_{p i}^{\ln p i} \quad \operatorname{dimana} \quad p i=\frac{u_{i}}{N}
$$

Keterangan :

$\mathrm{Pi}$ : proporsi jumlah individu ke-I dengan individu semua jenis

$\mathrm{H}^{\prime}$ : indeks keanekaragaman jenis

$\mathrm{Ni}$ : jumlah individu suatu jenis

$\mathrm{N}$ : jumlah individu seluruh jenis

Kriteria keanekaragaman menurut Magurran (1988) dibedakan menjadi 3 kategori, yaitu :

Keanekaragaman jenis tinggi, indeks $\mathrm{H}^{\prime}>3,5$

Keanekaragaman jenis sedang, indeks H' 1,5-3,5

Keanekaragaman jenis rendah, indeks $H^{\prime}<1,5$

Indeks keseragaman $(\mathrm{E})$

$$
(\mathrm{E})=\frac{\mathrm{H}^{\prime}}{\mathrm{H}_{\max }}
$$

nilai indeks keseragaman menurut Krebs (1985) berkisar antara 0 (nol) -1

(satu). Nilai indeks keseragaman dikategorikan sebagai berikut :

$0<\mathrm{E} \leq 0.5$ : Komunitas tertekan keseragaman rendah.

$0.5<\mathrm{E} \leq 0.75$ : Komunitas labil keseragaman sedang.

$0.75<\mathrm{E} \leq 1$ : Komunitas stabil keseragaman tinggi.

Analisi data parametrik : Data biotik berupa kelimpahan Makrobentos dianalisis menggunakan uji-t Student untuk membandingkan populasi data antara lokasi pertama (area monokultur) dan lokasi kedua (area referensi).

Rumus Uji-t :

$$
t=\frac{\bar{x}-\mu_{0}}{s / \sqrt{n}}
$$

Keterangan :

$\mathrm{t} \quad$ : $\mathrm{t}$ hitung

$\mathrm{x} \quad$ : rata-rata sampel

нo : rata-rata tertentu (yang menjadi perbandingan)

s $\quad$ : standart deviasi

sampel n: jumlah sampel

Untuk menghitung korelasi antara komponen biotik dan abiotik digunakan BIO-ENV pada software PRIMER V.6.1.5..

\section{HASIL DAN PEMBAHASAN}

Dari hasil penelitian yang dilakukan pada 2 stasiun yakni monokultur dan referensi di pulau Tembelas kabupaten Karimun, Kepulauan Riau. Ditemukan sebanyak 66 spesies terbagi dalam 5 kelas, 41 famili, dan 57 genus. Komposisi makrozoobentos yang diperoleh dari hasil penelitian dapat dilihat pada (Tabel.1). 
Tabel 1 Kelimpahan Makrobentos di kawasan non budidaya raferensi di Perairan pulau Tembelas, Kabupaten Karimun, Kepulauan Riau

\begin{tabular}{|c|c|c|c|c|c|c|c|c|c|}
\hline \multirow{3}{*}{ No } & \multirow{3}{*}{ Kelas } & \multirow{3}{*}{ Famili } & \multirow{3}{*}{ Genus } & \multicolumn{6}{|c|}{ Kelimpahan (per Grab) } \\
\hline & & & & \multicolumn{3}{|c|}{$\begin{array}{l}\text { Sampling } 1 \\
\text { Juni, 2016 }\end{array}$} & \multicolumn{3}{|c|}{$\begin{array}{c}\text { Sampling } 2 \\
\text { Oktober, } 2016\end{array}$} \\
\hline & & & & R1T1 & R2T1 & R3T1 & R1T2 & R2T2 & R3T2 \\
\hline 1 & Gastropoda & Ellobidae & Ellobium sp & 11 & 9 & 16 & 4 & 5 & 2 \\
\hline 2 & & Columbellidae & Costoanachis sp & 7 & 0 & 13 & 0 & 0 & 0 \\
\hline 3 & & & Parvanachis sp & 3 & 0 & 0 & 0 & 0 & 0 \\
\hline 4 & & Nassaridae & Nassarius sp & 24 & 3 & 21 & 4 & 0 & 2 \\
\hline 5 & & Muricidae & Ocinebrina sp & 2 & 0 & 0 & 0 & 0 & 0 \\
\hline 6 & & Ovulidae & Pellasimnia sp & 1 & 0 & 0 & 0 & 0 & 0 \\
\hline 7 & & Fissurellidae & Tugali sp & 0 & 0 & 0 & 0 & 0 & 1 \\
\hline 8 & & Mangeliidae & Agathotoma sp & 2 & 0 & 0 & 0 & 0 & 0 \\
\hline 9 & & & Pyrgocythara sp & 0 & 0 & 2 & 1 & 0 & 1 \\
\hline 10 & & Epitonnidae & Epitonium sp & 0 & 0 & 8 & 0 & 0 & 0 \\
\hline 11 & & Pyramidellidae & Boonea sp & 0 & 0 & 2 & 0 & 0 & 0 \\
\hline 12 & & & Odostomia sp & 1 & 0 & 1 & 0 & 0 & 0 \\
\hline 13 & & & Ericusa $\mathrm{sp}$ & 2 & 0 & 5 & 0 & 0 & 0 \\
\hline 14 & & & Murex sp & 1 & 0 & 0 & 0 & 0 & 0 \\
\hline 15 & & & Eupleura sp & 2 & 0 & 0 & 0 & 0 & 0 \\
\hline 16 & & & Ocinebrina sp & 2 & 0 & 0 & 0 & 0 & 0 \\
\hline 17 & & Marginellidae & Prunum sp & 3 & 0 & 2 & 0 & 0 & 0 \\
\hline 18 & & Turridae & Glyphoturris sp & 0 & 0 & 3 & 0 & 0 & 0 \\
\hline 19 & & Babyloniidae & Babylonia sp & 2 & 0 & 2 & 0 & 0 & 0 \\
\hline 20 & & Mitridae & Mitra sp & 1 & 0 & 0 & 0 & 0 & 0 \\
\hline 21 & & Skeneidae & Leucorhynchia sp & 1 & 2 & 2 & 0 & 0 & 0 \\
\hline 22 & & Naticidae & Naticarius sp & 0 & 0 & 1 & 0 & 0 & 0 \\
\hline 23 & & Turbinidae & Turbo sp & 1 & 0 & 0 & 0 & 0 & 0 \\
\hline 24 & & Trochidae & Austrocochlea sp & 0 & 0 & 2 & 0 & 0 & 0 \\
\hline 25 & & Trochidae & Clanculus sp & 0 & 1 & 0 & 0 & 0 & 0 \\
\hline 26 & & Batillariidae & Batillaria sp & 0 & 0 & 3 & 1 & 1 & 0 \\
\hline 27 & & Assimineidae & Assiminea $\mathrm{sp}$ & 10 & 0 & 1 & 0 & 0 & 0 \\
\hline 28 & Bivalvia & Lucinidae & Anodontia sp & 4 & 2 & 8 & 3 & 2 & 2 \\
\hline 29 & & & Lucina sp & 15 & 2 & 19 & 0 & 0 & 0 \\
\hline 30 & & Nuculoidae & Nuculana sp & 31 & 1 & 27 & 0 & 3 & 2 \\
\hline 31 & & Arcidae & Anadara sp & 16 & 5 & 9 & 0 & 0 & 0 \\
\hline 32 & & & Arca sp & 8 & 0 & 8 & 3 & 2 & 1 \\
\hline 33 & & Ostreidae & Ostrea sp & 2 & 1 & 5 & 0 & 0 & 0 \\
\hline 34 & & Nacellidae & Cellana sp & 7 & 0 & 6 & 2 & 0 & 0 \\
\hline 35 & & Neotiidae & Arcopsis sp & 16 & 0 & 19 & 0 & 0 & 0 \\
\hline 36 & & Crassatellidae & Crassatella $\mathrm{sp}$ & 2 & 0 & 0 & 0 & 0 & 0 \\
\hline 37 & & Fissurellidae & Diodora sp & 0 & 0 & 4 & 0 & 0 & 0 \\
\hline 38 & & & Emarginula sp & 1 & 0 & 0 & 0 & 0 & 0 \\
\hline 39 & Polychaeta & Nephtyidae & Nephtys sp & 1 & 0 & 1 & 0 & 0 & 0 \\
\hline 40 & & Nereididae & Namanereis sp & 0 & 2 & 0 & 0 & 0 & 0 \\
\hline 41 & & Capitellidae & Mediomastus sp & 0 & 0 & 1 & 0 & 2 & 1 \\
\hline \multirow[t]{3}{*}{42} & Crustacea & Penaidae & Penaeus sp & 1 & 0 & 0 & 0 & 1 & 0 \\
\hline & & Kelimpahan (K) & & 180 & 28 & 190 & 18 & 16 & 12 \\
\hline & & Jumlah Jenis (s) & & 30 & 10 & 26 & 7 & 7 & 8 \\
\hline
\end{tabular}




\begin{tabular}{lllllll}
\hline $\begin{array}{l}\text { Keanekaragaman } \\
\text { (H) }\end{array}$ & 2,81 & 2,02 & 2,83 & 1,83 & 1,80 & 2,02 \\
\hline $\begin{array}{l}\text { Keseragaman Jenis } \\
\text { (E) }\end{array}$ & 0,83 & 0,88 & 0,87 & 0,94 & 0,93 & 0,97 \\
\hline Dominansi (C) & 0,08 & 0,17 & 0,08 & 0,17 & 0,19 & 0,14 \\
\hline
\end{tabular}

Tabel 2 Kelimpahan Makrobentos di kawasan budidaya monokultur di Perairan pulau Tembelas, Kabupaten Karimun, Kepulauan Riau

\begin{tabular}{|c|c|c|c|c|c|c|c|c|c|}
\hline \multirow{3}{*}{ No } & \multirow{3}{*}{ Kelas } & \multirow{3}{*}{ Famili } & \multirow{3}{*}{ Genus } & \multicolumn{6}{|c|}{ Kelimpahan (per Grab) } \\
\hline & & & & \multicolumn{3}{|c|}{$\begin{array}{c}\text { Sampling } 1 \\
\text { Juni, } 2016\end{array}$} & \multicolumn{3}{|c|}{$\begin{array}{c}\text { Sampling } 2 \\
\text { Oktober, } 2016\end{array}$} \\
\hline & & & & M1T1 & M2T1 & M3T1 & M1T2 & M2T2 & M3T2 \\
\hline 1 & Gastropoda & Ellobidae & Ellobium sp & 0 & 2 & 2 & 0 & 0 & 0 \\
\hline 2 & & Columbellidae & Costoanachis sp & 0 & 12 & 12 & 0 & 0 & 0 \\
\hline 3 & & & Parvanachis sp & 0 & 0 & 0 & 2 & 0 & 2 \\
\hline 4 & & & Pyrene sp & 3 & 0 & 3 & 0 & 1 & 1 \\
\hline 5 & & & Mitrella sp & 0 & 0 & 0 & 0 & 2 & 2 \\
\hline 6 & & Nassariidae & Nassarius sp & 5 & 4 & 9 & 0 & 3 & 3 \\
\hline 7 & & Terebridae & Terebra sp & 0 & 0 & 0 & 0 & 2 & 2 \\
\hline 8 & & Pyramidellidae & Turbonilla $\mathrm{sp}$ & 0 & 0 & 0 & 0 & 3 & 3 \\
\hline 9 & & Cerithiidae & Clypeomorus sp & 0 & 2 & 2 & 0 & 0 & 0 \\
\hline 10 & & & Cerithium sp & 0 & 0 & 0 & 0 & 1 & 1 \\
\hline 11 & & Architectonicidae & Architectonica sp & 0 & 0 & 0 & 0 & 1 & 1 \\
\hline 12 & & Biccinidae & Neptunea sp & 0 & 2 & 2 & 0 & 0 & 0 \\
\hline 13 & Bivalvia & Lucinidae & Anodontia sp & 5 & 5 & 4 & 2 & 3 & 5 \\
\hline 14 & & Tellinidae & Tellina $\mathrm{sp}$ & 1 & 2 & 3 & 1 & 0 & 1 \\
\hline 15 & & Archidae & Anadara sp & 0 & 1 & 1 & 0 & 0 & 0 \\
\hline 16 & & Cardiidae & Fulvia sp & 0 & 1 & 1 & 0 & 0 & 0 \\
\hline 17 & Polychaeta & Lumbrineridae & Lumbrineris $\mathrm{sp}$ & 2 & 0 & 1 & 0 & 2 & 0 \\
\hline 18 & & Nereidae & Nereis $\mathrm{sp}$ & 8 & 5 & 5 & 2 & 3 & 1 \\
\hline 19 & & & Namanereis $\mathrm{sp}$ & 2 & 0 & 2 & 0 & 0 & 0 \\
\hline 20 & & Cossuridae & Cossuras sp & 0 & 3 & 0 & 0 & 0 & 0 \\
\hline 21 & & Capitellidae & Heteromastus $\mathrm{sp}$ & 0 & 2 & 0 & 0 & 0 & 0 \\
\hline 22 & & & Capitella $\mathrm{sp}$ & 2 & 0 & 2 & 0 & 0 & 0 \\
\hline 23 & Crustacea & Penaidae & Penaeus sp & 1 & 0 & 0 & 0 & 0 & 0 \\
\hline \multirow[t]{6}{*}{24} & Ophiuroidea & Ophiuridae & Ophioplocus sp & 0 & 7 & 0 & 0 & 0 & 0 \\
\hline & & Kelimpahan (K) & & 27 & 48 & 49 & 7 & 21 & 22 \\
\hline & & Jumlah Jenis (s) & & 10 & 15 & 14 & 4 & 10 & 11 \\
\hline & & $\begin{array}{l}\text { Keanekaragaman } \\
\left(\mathbf{H}^{\prime}\right)\end{array}$ & & 2,06 & 2,43 & 2,33 & 1,35 & 2,22 & 2,24 \\
\hline & & $\begin{array}{l}\text { Keseragaman Jenis } \\
\text { (E) }\end{array}$ & & 0,90 & 0,90 & 0,88 & 0,98 & 0,96 & 0,93 \\
\hline & & Dominansi $(\mathbf{C})$ & & 0,15 & 0,11 & 0,13 & 0,27 & 0,12 & 0,12 \\
\hline
\end{tabular}

Hasil penelitian pada lokasi referensi yang dilakukan dengan dua kali pengambilan sampel dan telah teridentifikasi dapat ditemukan 4 genus yaitu Gastropoda, Bivalvia, Polychaeta, dan Crustacea, spesies yang ditemukan sebanyak 42 spesies (Tabel 4.1). Pada lokasi referensi terdapat taksa dominan yaitu gastropoda (Ellobium sp) dan bivalvia (Nuculana sp) dimana taksa gastropoda dan bivalvia ini bahwa tipe substrat berpasir akan memudahkan moluska terutama kelas Gastropoda untuk mendapatkan suplai nutrisi, menyaring makanan dan air yang diperlukan untuk 
kelangsungan hidupnya. Kedua taksa dominan yang terdapat pada lokasi referensi ini dikenal sebagai taksa oportunistik yang dapat mendominasi struktur makrobentos pada lingkungan perairan yang mengalami gangguan lingkungan yang dapat disebebkan oleh adanya pengkayaan organik(Putro,2006).

Hasil penelitian yang terdapat pada lokasi monokultur yang dilakukan dengan dua kali pengambilan sampel dan telah teridentifikasi dapat ditemukan 5 genus yaitu Gastropoda, Bivalvia, Polychaeta, Crustacea dan Ophiuroidea, spesies yang ditemukan pada lokasi ini yaitu 24 spesies (Tabel 4.2). pada lokasi monokultur terdapat taksa yang mendominasi yaitu gastropoda (Costoanachis sp) dan bivalvia (Anodontia sp), loasi monokultur memiliki taksa oportunistik seperti pada lokasi referensi dimana taksa tersebut dapat hidup atau mendominansi struktur makrobentos pada lingkungan perairan yang terganggu oleh adanya pengkayaan organik.

Indeks ekologi struktur komunitas makrobentos

Hasil analisis data penelitian yang telah dilakukan, didapatkan nilai indeks keanekaragaman, indeks keseragaman, serta indeks dominansi.

Indeks keanekaragaman Shannon-Wiener (H') pada lokasi monokultur sebesar 2,43, sedangkan nilai indeks lokasi referensi memiliki nilai indeks lebih besar yaitu 2,83. Hal ini dikarenakan jumlah individu (N) pada lokasi referensi lebih stabil (merata) dibandingkan dengan jumlah individu pada lokasi monokultur. Nilai indeks keanekaragaman $\left(\mathrm{H}^{\prime}\right)$ berhubungan dengan kekayaan spesies pada lokasi tertentu, tetapi juga dipengaruhi oleh distribusi kelimpahan spesies (Magurran,1988).

Nilai indeks keseragaman yang paling tinggi terdapat pada lokasi monokultur sebesar 0,98, sedangkan nilai indeks keseragaman terendah pada lokasi referensi sebesar 0.97. Jost (2010) menyatakan bahwa nilai indeks pesebaran berkisar antara 0-1. Nilai pesebaran ini bergantung pada tingkat keanekaragaman spesies atau nilai indeks keanekaragaman $\left(\mathrm{H}^{\prime}\right)$.

Nilai indeks dominansi paling tinggi pada lokasi monokultur sebesar 0,27 , sedangkan nilai indeks dominansi di lokasi referensi sebesar 0,19. Indeks dominansi berdasarkan pendapat Yuliana et al. (2012), menggambarkan ada tidaknya spesies yang medominansi jenis yang lain. Hasil perhitungan menunjukan bahwa lebih banyak yang memiliki nilai yang mendekati 0 dibandingkan yang mendekati 1 dengan demikian dapat dijelaskan bahwa secara umum diperairan itu terdapat atau tidaknya jenis yang berdominansi. Nilai tertinggi terdapat pada lokasi monokultur hal ini kemungkinan adanya spesies yang dapat beradaptasi dengan kondisi lingkungan dan dapat berdominansi pada lingkungannya.

Berdasarkan hasil Uji $\mathrm{T}$ dengan taraf signifikan 95\% $(\alpha=0,05)$ pada lokasi monokultur dan referensi dari hasil Pengambilan sampel pertama maka didapatkan hasil nilai $\mathrm{p}<0,05$ sehingga terdapat perbedaan yang signifikan antara keanekaragaman makrobentos dengan waktu pengambilan sampel pada monokultur, sedangkan pada pengambilan sampel kedua hasil yang diperoleh adalah nilai $\mathrm{P}>0.05$, sehingga tidak terdapat perbedaan yang signifikan antara keanekaragaman makrobenthos dengan waktu pengambilan sampel MT2 dengan RT2. Hal ini kemungkinan karena pada T1 pengambilan sampel dilakukan pada musim kemarau, dimana kuat arus perairan cenderung rendah, sedangkan pada T2 pengambilan sampel dilakukan pada musim penghujan, dan kuat arus di perairan tinggi

\section{Kualitas Perairan Kawasan Budidaya dan Non- budidaya}

Berdasarkan hasil pada lokasi budidaya monokultur pada pengambilan sampel pertamana (T1), nilai DO pada kedalaman 3-5 meter sebesar 4,61 $\mathrm{mg} / \mathrm{L}$, sedangkan pada kawasan budidaya monokultur pengambilan sampel ke dua (T2), nilai DO sebesar 6,34 mg/L, pada kedalaman 3-5 meter. Sedangkan pada lokasi referensi pada pengambilan sampel pertama (T1) adalah 4,5 $\mathrm{mg} / \mathrm{L}$ pada kedalaman 3-5 meter. Nilai DO pada pengambilan sampel ke dua (T2) sebesar 6,13 mg/L. Hal ini menunjukan kandungan DO tergolong rendah pada lokasi monokultur, Oksigen terlarut pada lokasi referensi masih tergolong baik dan dapat menunjang kehidupan organisme akuatik. Barus (2004) menambahkan bahwa kehidupan organisme akuatik berjalan dengan baik dengan kandungan oksigen dalam air minimum sebesar $5 \mathrm{mg} / \mathrm{l}$. Rendahnya kandungan oksigen terlarut pada lokasi monokultur juga dapat disebabkan adanya 
penggunaan oksigen secara bersamaan oleh biota budidaya.

Hasil analisis kualitas suhu perairan pada lokasi monokultur pada waktu pengambilan sampel pertama (T1) suhu perairan sebesar $29,9^{\circ} \mathrm{C}$, sedangkan pada pengambilan sampel ke dua (T2) suhu perairan sebesar $31,43^{\circ} \mathrm{C}$ pada masing-masing pada kedalaman 5 meter. Sedangkan pada lokasi referensi, (T1) suhu perairan sebesar $30,13^{\circ} \mathrm{C}$, sedangkan suhu pada pengambilan (T2) sebesar $31,6^{\circ} \mathrm{C}$ Berdasarkan data pengamatan pada lokasi monokultur dan referensi tergolong hangat pada pengambilan sampel T2, karena bagian air langsung terkena paparan cahaya matahari. Egonmwan (2007) menambahkan bahwa peningkatan suhu air dapat menyebabkan penurunan kelarutan gas-gas yang terikat pada molekul air, di mana adanya kenaikan temperatur/suhu air menyebabkan terjadinya penurunan konsentrasi oksigen terlarut, umumnya beberapa organisme makrobenthos mampu toleran terhadap suhu yang hangat.

Hasil analisi salinitas pada lokasi budidaya monokultur (T1) sebesar 31 ppt pada kedalaman 3 meter, sedangkan pada monokultur waktu kedua (T2) salinitas air yaitu sebesar 30,6 ppt pada kedalaman 3 meter. Pengamatan di lokasi referensi (T1) salinitas air sebesar 30,6 ppt, serdangkan pada pengamatan kedua (T2) nilai salinitas yaitu 32,6 ppt masing-masing pada kedalaman 3 meter. Salinitas perairan laut di lokasi budidaya maupun nonbudidaya tergolong ideal. Idealnya perairan laut memiliki salinitas minimum 30-35 ppt (Munn, 2004). Salinitas pada lokasi monokultur memiliki nilai salinitas yang lebih rendah dibandingkan dengan salinitas pada lokasi referensi. Kadar salinitas perairan laut pada lokasi kawasan budidaya dapat dipengaruhi oleh adanya endapan bahan organik yang dihasilkan oleh biota budidaya pada lokasi tersebut.

Analisis tipe substrat pada sedimen dilakukan dengan analisis Sediment Grain Size (SGS) untuk mengetahui kandungan atau komposisi tipe substrat sedimen hasil sampling dari setiap lokasi. Berdasarkan hasil analisis SGS, didapatkan data kandungan/kadar pasir (sand), lanau dan lempung dari masing-masing lokasi. Hasil analisi sedimen menunjukan sedimen pada lokasi budidaya monokultur (T1) terdiri atas $0,5 \%$ pasir, $92,4 \%$ lanau dan $7 \%$ lempung. Sedangkan hasil pengambilan sampel kedua (T2) terdiri atas 8,6\% pasir, 90,4\% lanau dan 1\% lempung. Sedimen pada lokasi referensi pengambilan sampel pertama (T1) terdiri atas 0,5\% pasir, 92,5\% lanau dan 7\% lempung, sedangkan pengambilan sampel kedua (T2) yaitu $10,2 \%$ pasir, $87,8 \%$ lanau dan $2 \%$ lempung. Berdasarkan data SGS tersebut, dapat diketahui bahwa pada lokasi monokultur dan referensi tipe substrat yang mendominasi adalah lanau. lanau menunjukkan bahwa laju sedimentasi bahan organik pada kawasan monokultur tersebut tergolong lebih tinggi. Hal ini ditunjukkan oleh adanya kandungan lempung dan pasir yang paling tinggi pada lokasi monokultur. Menurut Supriharyono (2000), materi tersuspensi pada perairan dengan arus tenang akan mempercepat pengendapan materi organik, sedangkan pada arus yang deras laju sedimentasi akan lebih rendah. Arus pada lokasi monokultur tergolong lebih tenang dibandingkan dengan lokasi lainnya.

Materi organik pada substrat sampel sedimen pada penelitian ini dianalisis untuk mengetahui kandungan karbon dan nitrogen yang ada pada sedimen menggnakan analisis C/N Ratio. Substrat pada lokasi monokultur pada pengambilan sampel pertama (T1) memiliki konsentrasi karbon (C) sebesar 2,88\% dan konsentrasi nitrogen $(\mathrm{N})$ sebesar $0,41 \%$, sedangkan substrat pada pengambilan sampel kedua (T2) memiliki konsentrasi karbon (C) sebesar 12,8\% dan konsentrasi nitrogen $(\mathrm{N})$ sebesar $1,13 \%$. Materi organik pada substrat sampel sedimen pada lokasi referensi hasil sampel (T1) memiliki konsentrasi karbon (C) sebesar 3,87\% dan konsentrasi nitrogen $(\mathrm{N})$ sebesar $0,37 \%$. Hasil substrat pengambilan sampel kedua (T2) memiliki konsentrasi karbon (C) sebesar 9,78\% dan konsentrasi nitrogen (N) sebesar 1,16\%. Berdasarkan data tersebut, dapat diketahui bahwa pada kedua lokasi memiliki C/N ratio $<10 \%$, yang mengindikasikan bahan-bahan organik (organic materials / OM) berasal dari laut. Konsentrasi C lebih tinggi dibandingkan kandungan $\mathrm{N}$ pada substrat di kedua lokasi. Konsentrasi $\mathrm{C}$ yang lebih tinggi disebabkan adanya akumulasi limbah atau sisa materi organik, serta pengkayaan nutrien pada proses dekomposisi limbah di dalam perairan (Eleftheriou, 2013). Bahan organik pada substrat dibutuhkan sebagai sumber makanan bagi organisme makrobenthos, yang kemudian akan 
mempengaruhi jumlah populasi organisme benthos di dasar perairan.

Hasil parameter fisika dan kimia yang didapatkan pada lokasi monokultur dan referensi berdasarkan area (Gambar 4.1) dan waktu (Gambar 4.2) di analisis mengunakan Principle Component Analysis (PCA) oleh aplikasi Primer V.1.6.

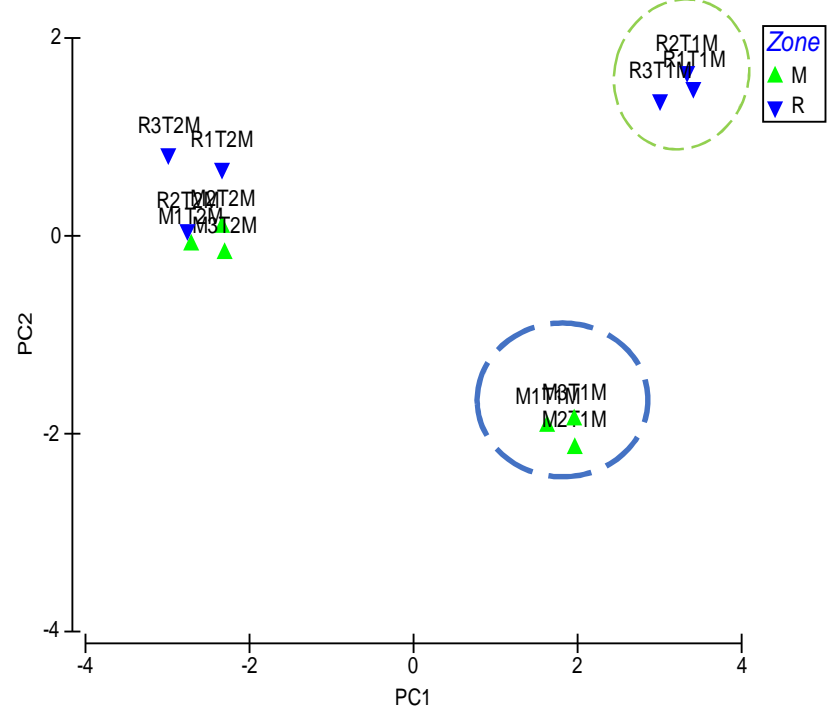

Gambar 1 Hasil analisi Principle Component Analysis (PCA) parameter fisika dan kimia yang didapatkan pada lokasi monokultur dan referensi berdasarkan area

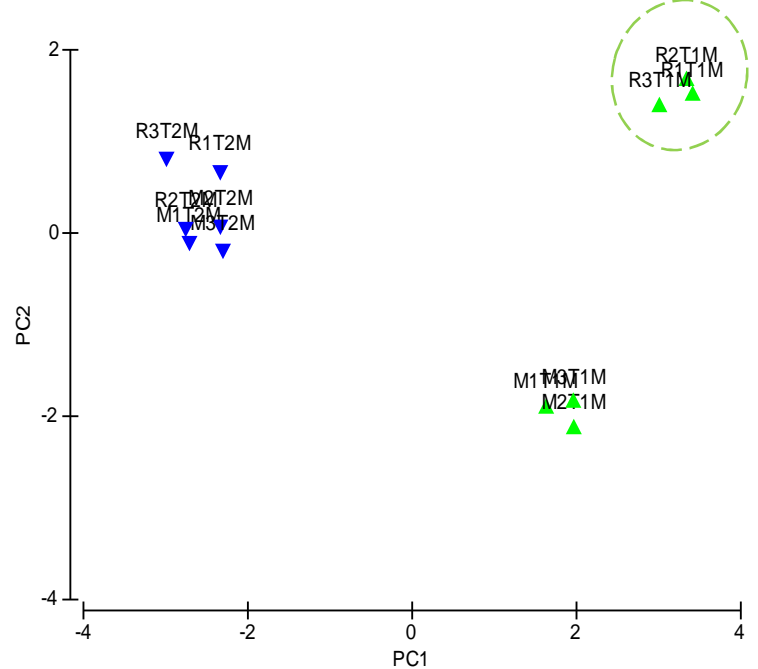

Gambar 2 Hasil analisi Principle Component Analysis (PCA) parameter fisika dan kimia yang didapatkan pada lokasi monokultur dan referensi berdasarkan waktu
Hasil analisis menunjukan adanya perbedaan antar waktu sampling, yang ditunjukan oleh adanya pengelompokan pada ordinat-ordinat berdasarkan waktu, namun tidak di tunjukan adanya perbedaan yag nyata antar lokasi. Hasil menunjukan tidak memiliki perbedaan diantara area perairan pada monokultur dan referensi sehingga tidak ada perbedaan yang nyata. Hal ini sesuai dengan pendapat Putro (2014), secara umum kondisi perairan dikedua lokasi relatif sama, dengan sedikit variabelitas nilai. Pengelompokan terjadi pada waktu sehingga mengidikasikan bahwa nilai- nilai parameter fisika-kimia periran berfluktuasi dari waktu ke waktu, dan masih relatif kondusif untuk area budidaya.

Hubungan makrobentos dengan faktor fisikakimia, substrat sedimen, serta komposisi karbon, nitrogen di analisis mengguakan BIO-ENV yang terdapat pada software PRIMER V.6.1.5.

Tabel 3. Hasil analisis hubungan kelimpahan monokultur dan referensi menggunakan BIO-ENV Software PRIMER V.6.1.5

\begin{tabular}{cclc}
\hline No & Korelasi $(\mathrm{r})$ & Variable & Jumlah Variable \\
\hline 1 & 0,561 & 8 & 1 \\
2 & 0,551 & $4 ; 6$ & 2 \\
3 & 0,522 & $4-6 ; 8$ & 4 \\
4 & 0,520 & $2 ; 4 ; 6 ; 8$ & 5 \\
5 & 0,518 & $4 ; 6 ; 8$ & 3 \\
6 & 0,516 & $4 ; 6 ; 8 ; 10$ & 4 \\
7 & 0,513 & $5 ; 6 ; 8$ & 3 \\
8 & 0,511 & $4 ; 6 ; 7 ; 9$ & 4 \\
9 & 0,511 & $4 ; 6 ; 9$ & 3 \\
10 & 0,511 & $5 ; 6$ & 2 \\
\hline
\end{tabular}

Keterangan Variable:

1. Dissolved Oxygen $(\mathrm{mg} / \mathrm{l})$

2. Salinitas (ppm)

3. $\mathrm{pH}$

4. Konduktivitas $(\mathrm{S} / \mathrm{m})$

5. Temperatur $\left({ }^{\circ} \mathrm{C}\right)$

6. Turbiditas (NTU)

7. Pasir (\%)

8. Lanau (\%)

9. Lempung $(\%)$

10. Karbon

11. Nitrogen

Hasil yang terdapat pada Tabel 4.5 menunjukan nilai korelasi tertinggi ditunjukan pada korelasi 0,561 yaitu lanau yang memiliki arti 
karbon dan lanau mempengaruhi struktur komunitas makrobentos. Hal ini menunjukan bahwa adanya pengaruh terhadap struktur komunitas makrobentos pada area monokultur dan referensi, jika nilai korelasi semakin tinggi maka semakin besar hubungan antara faktor biotik dan abiotik tersebut. Substrat yang terdapat paling tinggi yaitu lanau, hal ini disebabkan adanya laju sedimentasi bahan organik yang tinggi. Hal ini sesuai dengan pernyataan Supriharyono (2000), bahwa terdapatnya kandungan lumpur dan tanah liat menghasilkan laju sedimentasi yang tinggi karena dipengaruhi oleh arus perairan.

\section{KESIMPULAN}

Struktur

komunitas makrobenthos monokultur dan referensi terdiri atas kelas Gastropoda, Bivalvia, Polychaeta, Crustacea dan Ophiuroidea. Makrobenthos yang dominan ditemukan pada lokasi monokultur dan referansi adalah gastropoda dan bivalvia Indeks keanekaragaman referensi memilki nilai yang lebih tinggi yaitu 2,83 dibandingkan dengan monokultur sehingga di kategorikan keanekaragaman jenis sedang. Pada tingkat kemerataan dan dominansi monokultur memiliki nilai yang lebih tinggi dibandingkan dengan referensi yaitu 0,98 memiliki dan 0,27 sehingga dikategorikan merata dan tidak ada jenis yang medominansi.

Kualitas perairan tidak terdapat perbedaan yang mencolok antara lokasi monokultur dan referensi namun terdapat perbedaan nyata antar waktu pengambilan sampel yang diindikasikan dengan adanya pengelompokan pada ordinasi (analisis PCA).

Hubungan antara faktor biotik dan abiotik sruktur makrobentos terdapat pada nilai korelasi tertinggi yang ditunjukan pada kandungan lanau yaitu (BIOENV $r=0,561$ ). Hal ini menunjukan adanya pengaruh terhadap struktur komunitas makrobentos pada area monokultur dan referens.

\section{DAFTAR PUSTAKA}

Asra, R. 2009. Makrozoobentos sebagai Indikator Biologi dari Kualitas Air di Sungai Kumpeh dan Danau Arang-Arang Kabupaten Muaro Jambi, Jambi. Biospecies, 2 (1): 23-25.
Egonmwan, R. I. 2007. Thermal Tolerance and Evaporative Water Loss of the Mangrove Prosobranch Tympanotonus fuscatus var. radula L. (Cerithiacea: Potamididae). Pakistan Journal of Biological Sciences 10(1): 163-166.

Eleftheriou, A. 2013. Methods for The Study of Macrobenthos, Fourth Edition. John Wiley \& Sons, Ltd. Oxford

Jost, L. 2010. The Relation between Evenness and Diversity. Diversity (2): 207-232.

Krebs, C.J. 1985. Ecology. The Experimental Analisys of Distribution and Abudance. Third Edition. Harper \& Raws Publishers. New York.

Magurran, A. E. 1988. Ecological diversity and its measurement. Princeton University Press, New Jersey: $\mathrm{x}+179 \mathrm{hlm}$.

Munn CB. 2004. Marine eukaryotic microbes. In Marine Microbiology-Ecology and its Applications. London (UK): Garland Science BIOS Scientific Publishers.

Odum. 1993. Dasar-dasar Ekologi. Edisi Ketiga. Alih Bahasa T. Samingan. Gadjah Mada University Press. Yogyakarta.

Putro, S.P. dan Suhartana. 2008. Rehabilitas dan Optimalisasi Pemanfaatan Sumber Daya Alam Kawasan Rawapening Dengan Menerapkan Menajemen Lingkungan dan Ecological Engineering Dalam Upaya Meningkatan Kesejahteraan Masyarakat. Laporan KKN PPM -DP2M DIKTI, Lemlit Undip. Semarang.

Putro, S.P. 2014. Metode Sampling Penelitian Makrobentos dan Aplikasinya. Graha Ilmu. Yogyakarta.

Wijayanti, P.D, S.P Putro dan Suhartana. 2009. Optimalisasi Pemberdayaan Masyarakat Desa Asinan, Kecamatan Bawen, Kabupaten Semarang Melalui Pengembangan Teknik Budidaya Sistem Keramba Apung dan Peningkatan Mutu Pakan Ikan. Laporan KKN PPM -DP2M DIKTI, Lemlit Undip. Semarang. 
Perawati \& Mochamad Hadi 